\title{
The renewal of the digital humanities. An overview of the transformation of professions in the humanities and social sciences
}

\author{
Marie-Laure Massot ${ }^{1}$ and Agnès Tricoche ${ }^{2}$ \\ 1 CAPHÉS, CNRS-ENS, Paris, France \\ 2 AOROC, CNRS-ENS-EPHE, Paris, France \\ *Corresponding author: marie-laure.massot@ens.psl.eu
}

\begin{abstract}
This article presents a study of the French-speaking digital humanities. It is based on the experience of two research engineers from the French National Center for Scientific Research (CNRS) who have been studying these issues for the last ten years. They conducted a survey at the École Normale Supérieure (ENS-Paris) which enabled them to draw up an overview of the transformation of the profession of humanities and social sciences research engineers in the context of the digital humanities. The Digit_Hum initiative, which they run in parallel with their respective activities at the ENS, also provided information for this overview thanks to its role as a space for discussion about the digital humanities along with training and structuring of this field at the ENS and the Université Paris Sciences \& Lettres (PSL).
\end{abstract}

\section{Keywords}

Digital humanities; Humanities and social sciences engineer; Digit_Hum initiative; École Normale Supérieure; Survey.

Digital technology has transformed working methods and how scientific results are published in the humanities and social sciences (HSS). In this context, the role of the HSS research engineer is constantly changing and exists at the crossroads of the humanities and the digital sphere. There is an ongoing transformation of knowledge and professions which means that research support profiles are seeing their disciplinary boundaries evolve: without having lost their technical and disciplinary specificities, the professions are increasingly seeing the digital component impose itself as a daily work necessity, with which it is necessary to redefine oneself in part, to reinvent one's mode of operation, one's tools, one's methodological approaches. Who are the actors involved in digital humanities projects? What is the role of the HSS research engineer in this new landscape? What skills do they need to respond to the digital challenge? What might the typical profile of a "digital humanities" engineer be?

The ideas developed in this paper are based on the experience of two research engineers with the French National Center for Scientific Research (CNRS) who have been working with these issues for the last ten years ${ }^{1}$. The Digit_Hum initiative, which they run in parallel with their respective activities at the École Normale Supérieure (ENS), also provides information for this overview as it offers a space for discussion about the digital humanities along with training and structuring of this field at the ENS and the Université Paris Sciences \& Lettres².

\footnotetext{
${ }^{1}$ Marie-Laure Massot is head of the "Humanités numériques et valorisation de corpus" initiative at the CAPHÉS (History and Philosophy of Science Archives Centre) which provides scientific and technical support for print and digital publishing projects led by ENS research teams. Agnès Tricoche is co-head of the Digital Humanities pole of the AOROC (Archaeology and Philology of the East and West) laboratory after having worked for 6 years as a database engineer at the TransferS Laboratory of Excellence (Investments for the Future programme ANR-10-IDEX-0001-02 PSL* and ANR-10-LABX-0099).

${ }^{2}$ The Digit_Hum Initiative began in 2014 and involves annual workshops, portraits and a survey. Its website also provides information and training resources along with a portfolio of drawings, some of which have been used to illustrate this article.
} 
"A new kind of digital humanist is emerging who combines in-depth training in a single humanist subfield with a mix of skills drawn from design, computer science, media work, curatorial training, and library science." Digit_Humanities, p. 116 [Burdick, A. and al., 2012].

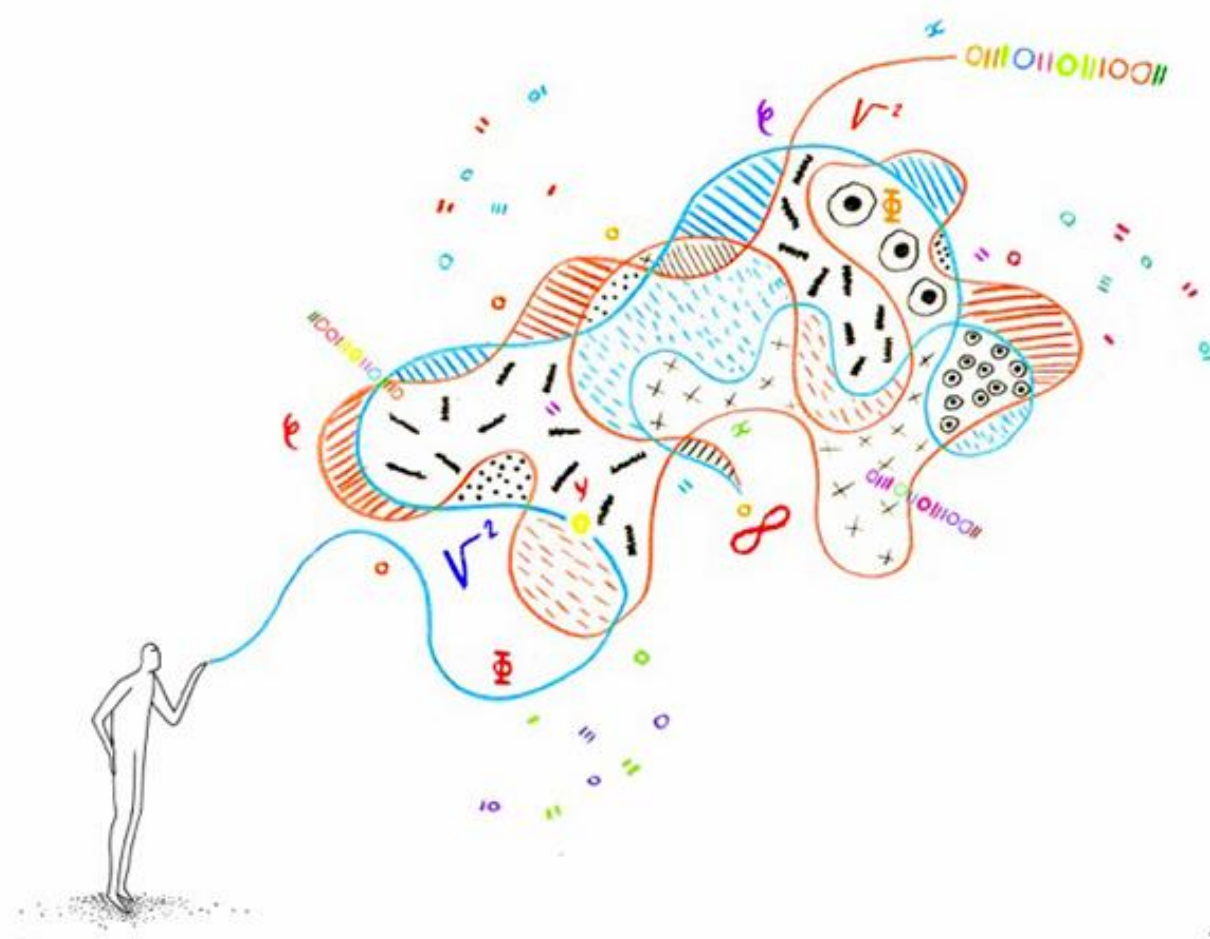

Figure 1. Drawing the digital humanities (Saint-Oma, 2019) $)^{3}$.

It is not an easy task to define the digital humanities and report on their unifying factors despite their diversity. The frontier of digital humanities is extremely shifting and divisive. In the philological field, for example, it appears as a space relay, a medium that, in the collaboration between the researcher and the engineer, gives to see differently and to analyze the data. But according to other disciplinary points of view, the digital humanities are not able to propose a complete data analysis process, as the statistician or the geomatician does with his tools and specific disciplinary competences, which are more related to the hard sciences ${ }^{4}$. In the context of this article, the authors voluntarily consider the expression "digital humanities" in its broadest sense, in order to take into account the diversity of perceived or experienced realities: it is the exploitation of digital tools in the intellectual process of production and analysis of humanities and social sciences, an alliance whose objective is to optimize the potential of exploitation and valorization of scientific data. In no way does this article claim to give a firm and immutable definition of the field of digital humanities, but rather aims to engage in a reflection on the practices that have emerged over the past several years.

This initiative is coordinated by the two authors of this article in collaboration with Julien Cavero (MOM). It has numerous partners and a significant network (EUR Translitterae, ANR-10-IDEX-0001-02 PSL* and ANR-17-EURE-0025 future investment programme, GTHN Working Group, CNRS laboratories, etc.).

${ }^{3}$ The artist Saint-Oma, whose two drawings are reproduced in this article, graphically declines the digital humanities and the portraits of digital humanists. These meaningful drawings contribute to embodying digital humanities by tracing the contours of professions in deep mutation. Gathered in the portfolio of the Digit_Hum Initiative, these graphic traces offer a look at digital humanities and their actors, between knowledge and know-how (https://digithum.huma-num.fr/portfolio/saintoma/ consulted on 09/07/2021).

${ }^{4}$ We thank Damien Cartron, sociologist at the Maurice Halbwachs Center (CNRS-ENS-EHESS), for giving us his opinion on this question. 
At first glance, the humanities - tradition of arts, letters and books - seem diametrically opposed to digital, computer and network technology. Things are somewhat different for some social science disciplines (economics, sociology), whose production and analysis of quantitative data rely on methods and tools involving computer science. However, whether in the humanities or the social sciences, digital humanities are creating a deep interdisciplinary dialogue ${ }^{5}$ on the challenges of digital technology and are renewing the methodology for collecting, analyzing, enhancing and publishing data ${ }^{6}$. This "zone of exchange" ${ }^{7}$ does not just involve using new tools for pre-existing research practices. It also represents the creation of a new field of investigation and a new relationship between science and technology, researchers and engineers, knowledge and applications. Who are the actors involved in a digital humanities project? What role can humanities and social sciences research engineers play in this constantly evolving field? How should a digital humanities expert be trained? The following article attempts to answer all these questions and is based on a survey with 67 respondents about digital humanities actors and activities at the École Normale Supérieure. It was run by the Digit_Hum initiative between July 2017 and June $2018^{8}$.

\section{DIGITAL HUMANITIES ACTORS: BETWEEN KNOWLEDGE AND KNOW-HOW}

The digital humanities have paved the way for a dialogue between disciplines, theories and applications by developing new tools, objects or systems that enable us to obtain a different view and make things visible that were previously hidden with the book format ${ }^{9}$. This new digital medium opens up another intelligible world along with new horizons of knowledge. It also represents a whole new dimension offered to us for our work and relationships with others. The isolated humanities and social sciences researcher or engineer working exclusively in a library is now pretty much a thing of the past. Gradually, a team approach which combines the know-how of several actors has become established in HSS laboratories. The research team (researchers, academics and students) and their support team (engineers, technicians, librarians and document specialists) collaborate, communicate their knowledge and know-how and share tools and work methods. Interactions of this sort were already well established in disciplinary fields like geography or archaeology and in recent years they have strongly developed in fields like history and philosophy. This context means it is not a simple task to identify the actors of a digital humanities project. This was the subject of two Digit_Hum study days, in 2015, "Paysage et structuration des humanités numériques à l'ENS" (Landscape and structuring of digital humanities at the ENS) and in 2017, "Data deluge: quelles compétences pour quelles

\footnotetext{
${ }^{5}$ [Schmitt, E., 2017] p. 25, distinguishes between collaboration and interdisciplinarity: "(...) interdisciplinarity combined with computing requires computing to be considered as a scientific discipline without which there can be collaboration projects between actors but no dialogue between disciplines." see [Bénel, A., 2013] p. 106: "interdisciplinarity cannot succeed without mutual enrichment".

6 "What is Digital Humanities? Digital Humanities refers to new modes of scholarship and institutional units for collaborative, transdisciplinary, and computationally engaged research, teaching, and publication. Digital Humanities is less a unified field than an array of convergent practices that explore a universe in which print is no longer the primary medium in which knowledge is produced and disseminated. (...). Digital Humanities is defined by the opportunities and challenges that arise from the conjunction of the term digital with the term humanities to form a new collective singular." [Burdick, A. et al., 2012]. ${ }^{7}$ On this subject see [Dacos, M. and Mounier, P., 2014] p. 16.

${ }^{8}$ The whole survey - including the methodology, results, list of activities (research projects, scientific events and training courses) and an interactive graph of the institutional network - can be consulted on the Digit-Hum website (https://digithum.huma-num.fr/enquete/ consulted on 16/04/2021) or as a booklet: see [Massot, M.-L. and Tricoche, A., 2018].

${ }^{9}$ We shall cite as an example the Foucault's Reading Notes (FFL) project which has digitised, described and put online Michel Foucault's 20,000 reading notes. It has also developed digital tools to better understand and analyse the philosopher's reading practices and the development of his thought process: https://eman-archives.org/Foucault-fiches/ consulted on 16/04/2021). See [Massot, M.-L., Sforzini, A., Ventresque, V., 2019].
} 
données ?" (Which skills for what data?) ${ }^{10}$. Portraits of actors in the field were drawn up in the framework of this initiative and these testify to the diversity of these people's career paths, objectives, skills and roles ${ }^{11}$.

The survey of the digital humanities run at the École Normale Supérieure between 2017 and 2018 enabled us to gain very tangible understanding of the actors and activities which exist in this field. 67 researchers, teachers, engineers, technicians, library staff and students were identified as being involved in activities linked to the digital humanities (structuring and development of tools, enrichment, visualisation, etc.). The CNRS is by far the most highly represented organisation (over two thirds), with laboratories which mainly belong to firstly Literature and Languages departments and secondly Sciences of Antiquity departments ${ }^{12}$. The research units with the greatest presence in the survey bring together researchers who extensively use digital humanities tools for their research projects. These include databases, visualisation tools, geographic information systems, automatic data processing, online publication of digital corpora and so forth. These teams also have engineers whose work is directly related to computer science and digital technology (computer specialist, database engineer, data production and processing engineer, etc.) ${ }^{13}$. Processing the responses to the survey questionnaires also provided us with an enhanced understanding of how diverse and polymorphous are the functions and professions exercised by the actors in the digital humanities, the skills deployed, and the tools manipulated (Figure 2).

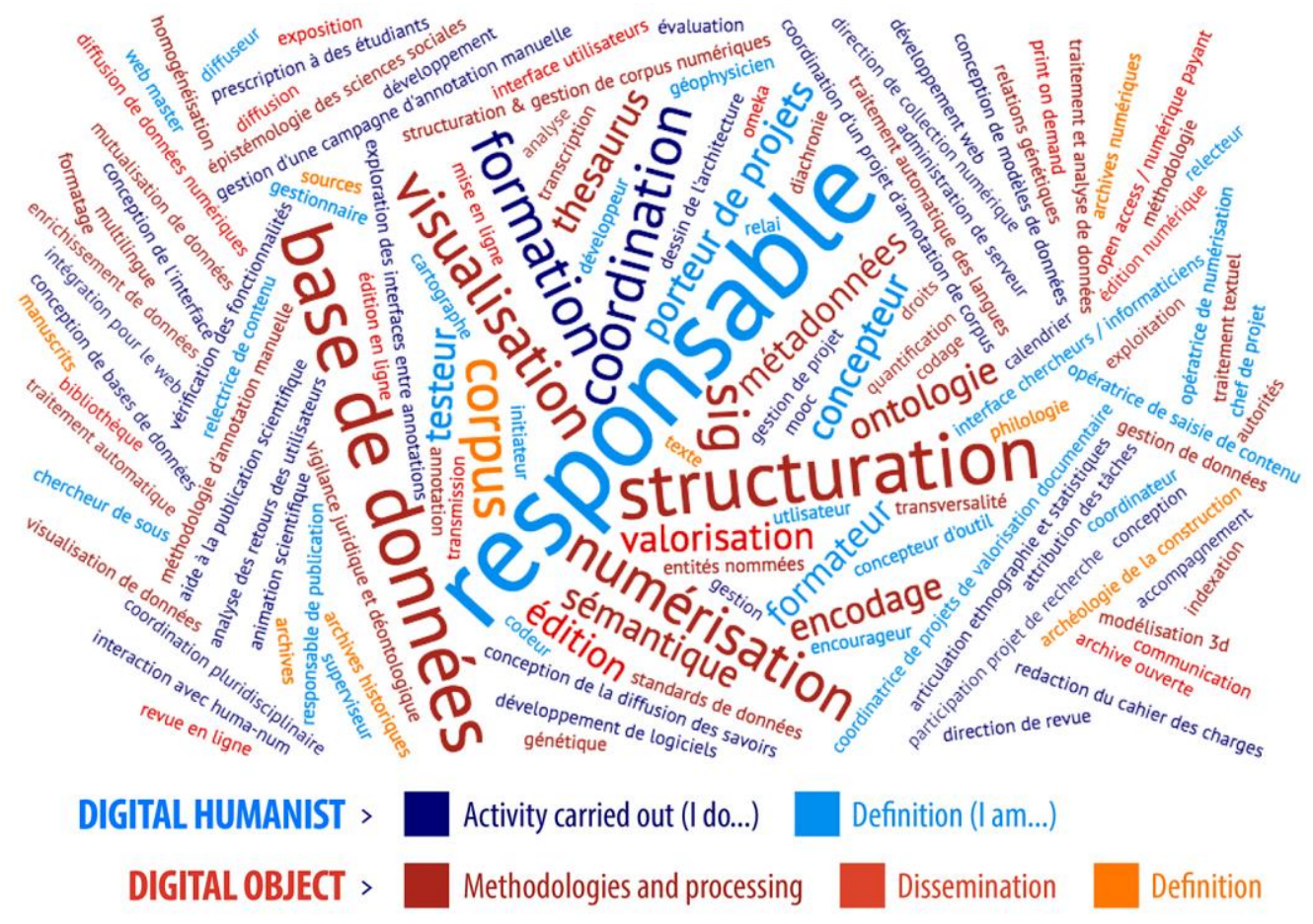

Figure 2. A cloud of keywords on the work functions of digital humanities actors at the ENS. Result of the Digit_Hum survey (July 2017-June 2018).

\footnotetext{
${ }^{10}$ These annual study days called "Ateliers Digit_Hum" enable participants to present digital analysis and valorisation projects in the HSS. Videos of the presentations are available online: https://digithum.huma-num.fr/atelier consulted on 16/04/2021.

${ }^{11}$ See https://digithum.huma-num.fr/portraits consulted on 16/04/2021.

12 These are the AOROC (Archaeology and Philology of the East and West, UMR CNRS/ENS / EPHE), ITEM (Institute of texts \& modern manuscripts, UMR CNRS / ENS) and Lattice (Languages, texts, computer processing and cognition, UMR CNRS / ENS / Univ. Paris 3 Sorbonne Nouvelle) laboratories. A list and short presentation of their work is available thanks to the Digit_Hum initiative's list.

13 See the reference list of research professions on the French Research Ministry website, RéFérens III: https://data.enseignementsup-recherche.gouv.fr/pages/referens/ consulted on 16/04/2021.
} 
The respondents are anthropologists, archaeologists, historians, philosophers (research and teaching professions). They are also cartographers, specialized in ancient sources, in linguistics or in data processing (research support professions). Computer science, scientific and technical information (archivists, librarians, documentalists) and publishers are also represented. It is clear from this survey that for most of them, digital humanities have profoundly changed their working methods and practices, on the one hand by reinforcing collaborative work, and on the other hand by facilitating access to sources, automatic processing, and the development of collections and data. In this context, we noted in particular the "manager" plays a central role in such projects as several actors, professions and skills need to be coordinated effectively. Few of the respondents had received initial training in digital humanities; on the other hand, many had received training as part of their professional training, or in a self-taught manner (face-toface or in the form of online tutorials).

The aim of this type of survey is not to provide a complete and exhaustive overview of the digital humanities but it does nonetheless undoubtedly reveal trends in the field. One of these is the federating role played by the research support professions, particularly of HSS engineers ${ }^{14}$. The list of activities drawn up in the framework of the survey is made up of 76 actions (mainly research projects but also scientific events and training). The data collected made it possible to represent the institutional network of the digital humanities at the ENS in 2018. It also clearly shows the extreme diversity of collaboration projects with other French, European and other international organisations in the framework of digital humanities activities at the ENS (Figure 3).

This survey ${ }^{15}$ contributes to a better understanding of the role of the engineer in the humanities and social sciences. Research support functions have long been considered as accessories which serve researchers or professors but they are becoming an integral part of the research process in the context of digital humanities. The research assistant of the past supported researchers in their daily work but these have now been replaced by real autonomous collaborators who contribute their own expertise, technicality, tools, methods, language, vocabulary and even grammar to research. This transversal job profile acts as a link between the different people involved in digital humanities projects. It is essential to ensure the transmission between the knowledge of researchers and the know-how of people in research support functions (engineers, computer scientists, librarians, document specialists, archivists, web designers, entrepreneurs, legal specialists, etc.). Researchers are like the true "orchestral conductors" of science and contribute their extensive knowledge of a corpus, a discipline and its essential questions but engineers provide their tools, wealth of experience and networks to bring a project to a successful conclusion. This encounter between knowledge and know-how, knowledge and experience, expertise and practice, opens up new horizons for research in which the engineer is now the key player. In this way, the digital humanities mean we have to work differently by encouraging a dialogue between disciplines and between professionals.

\footnotetext{
${ }^{14}$ The diversity of HSS engineers' careers, occupations and functions is also highlighted effectively by the portraits drawn up after the survey in the framework of the Digit_Hum initiative: https://digithum.huma-num.fr/portraits/consulted on 16/04/2021 (see Research Support Staff in particular).

${ }^{15}$ For more information on the survey and its methodology, see: https://digithum.huma-num.fr/enquete/methodologie/ consulted on 16/04/2021.
} 


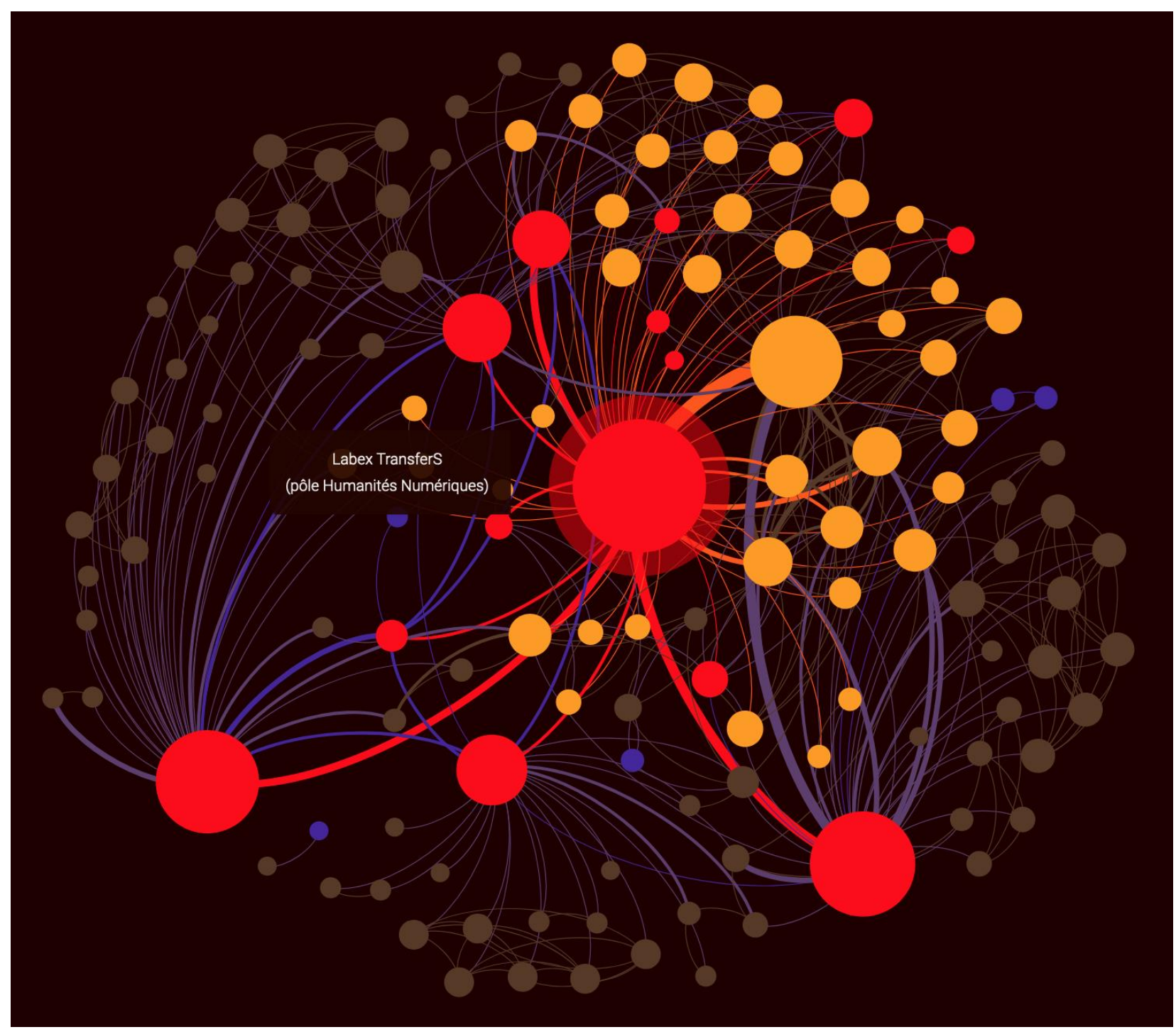

Figure 3. Interactive graph of the institutional network of digital humanities at the ENS. (https://digithum.huma-num.fr/enquete/reseau/).

Here with the example of the labex TransferS (red central circle with shadow) and its collaborations within (red circles) or outside (yellow circles) ENS laboratories.

Result of the Digit_Hum survey (July 2017-June 2018).

\section{DISCIPLINE VERSUS TECHNIQUE: THE EVOLUTION OF THE ENGINEER'S ROLE IN THE DIGITAL CONTEXT}

The professions of research and training engineers and technicians (ITRFs is the French acronym) and research engineers and technicians (ITAs) are constantly evolving. These are described in RéFérens (see footnote 13 above), the directory of branches of professional activity (BAPs) and higher education job types, which is updated regularly. BAP D covers the humanities and social sciences ${ }^{16}$ and is currently made up of four families of professional activities and seventeen job types reflecting the diversity of its agents' job functions and professions.

\footnotetext{
16 "Between knowledge and know-how, disciplinary skills and technical skills, the professions of engineers and technicians in the humanities and social sciences". See BAP D:

https://data.enseignementsup-recherche.gouv.fr/pages/la_bap/?refine.referens_bap_id=D consulted on 16/04/2021.
} 
At first glance, this group of professions seem rather disparate but their common specific feature seems to be the strong disciplinary competence and diversity of profiles. This was made clear by the CNRS's 2012 report on the "BAP D" branch of professional activity - "Entre savoirs et savoir-faire, compétences disciplinaires et compétences techniques, les métiers des ingénieurs et techniciens en sciences humaines et sociales" ${ }^{17}$. This report clearly shows the unifying role of the HSS engineer in research laboratories and also highlights their ambivalent status: discipline versus technique, versatility versus pluriactivity. There are indeed very varied professional profiles within BAP D - anthropologists, archaeologists, cartographers, codicologists, geographers, economists, historians, linguists, philologists, psychologists, economists, etc. Often those in these professions have strong disciplinary skills. However, computerisation and the introduction of NICTs (new information and communication technologies) have radically changed professions in the humanities, often involving increased technical skills (Figure 4). "For example, cartographers now all work on computers because geography has undergone a major technical evolution with the appearance of geomatics, namely the creation of databases made up of georeferenced elements (...)" ${ }^{18}$.

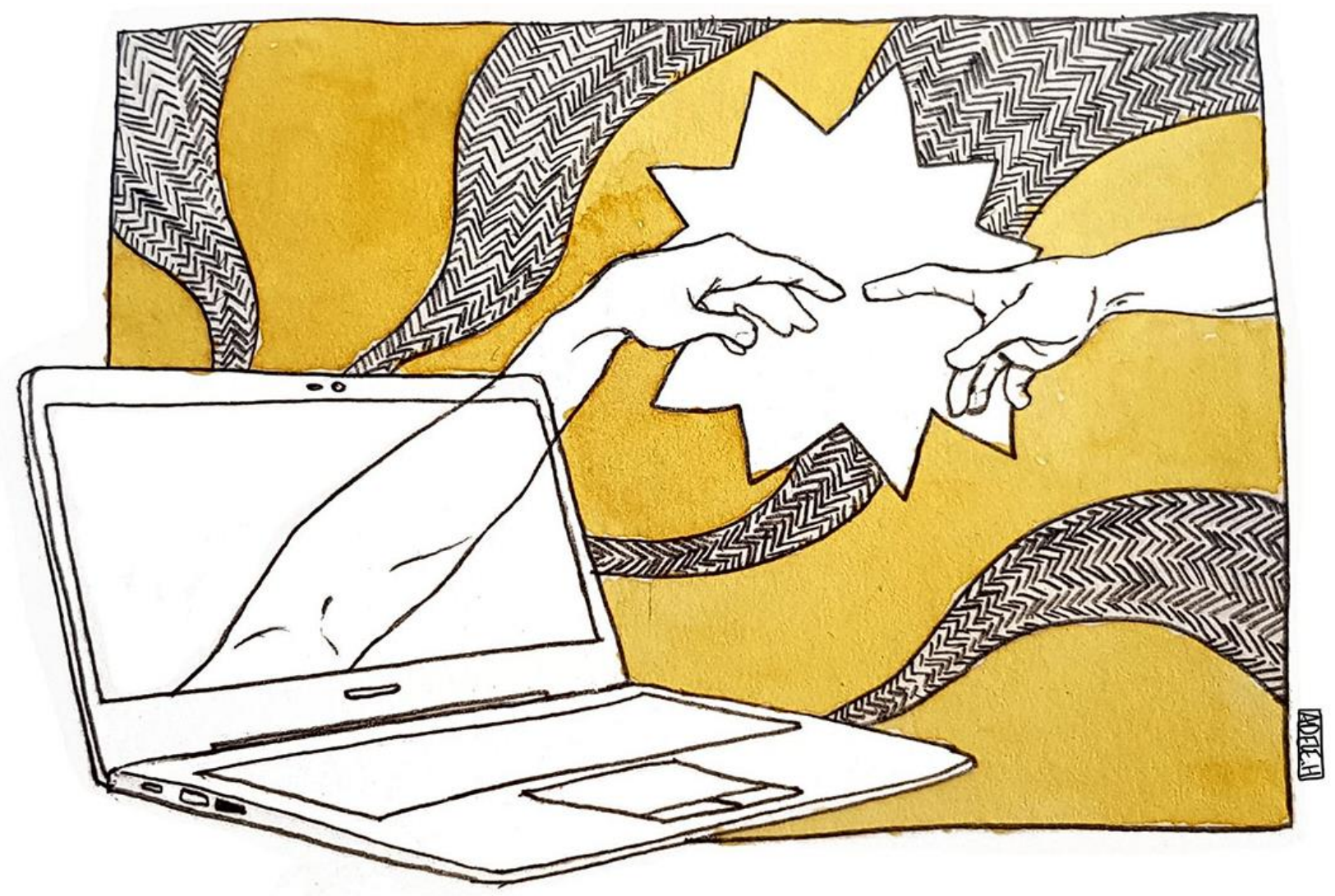

Figure 4. Computerisation and the introduction of NICTs (Adèle Huguet, 2020) ${ }^{19}$.

\footnotetext{
${ }^{17}$ Study ordered by the Observatory of Employment and Scientific Professions's Steering and Monitoring Committee. It should be noted that the BAP D report, published ten years ago, mentioned the term "Digital Humanities" three times and presented it as an emerging field with cross-cutting competencies: "New fields are emerging such as Digital Humanities which are at the intersection of BAP D and F, or even E. This field brings together research, methods and digital tools applied to the humanities and social sciences." (quote translated by the autors). [Cartron, D. et al., 2012, p. 70-71].

${ }^{18} \mathrm{Ibid}, \mathrm{p} .83$.

${ }^{19}$ Adèle Huguet, scientific mediator, uses drawing and comics to transmit scientific ideas and knowledge. Find her work in the Digit_Hum portfolio or on her website: adelehuguet.wordpress.com consulted on 15/07/2021.
} 
This change in the activities of engineers and, indeed, researchers, has contributed to increasing the "porosity" between branches of professional activity and between the roles of engineers and researchers. Nevertheless, although researchers are increasingly interested in technology and engineers are becoming more and more expert in a discipline, their activities and roles remain well defined. The report on BAP D stresses that "The profession of a researcher is not simply characterised by strong disciplinary competence but first and foremost by the responsibility for driving and then leading innovative lines of research". The role of HSS engineers ${ }^{20}$ in the context of digital humanities is therefore to support researchers by guiding them in this new world and to initiate this transfer between disciplines and techniques, knowledge and applications. For example, in the context of statistical data processing or the setting up of databases, engineers need to use their professional know-how and mastery of best practices to support researchers. They guarantee the interoperability, durability and reuse of research data by transmitting their knowledge of models and languages.

What knowledge and skills should this "dialogue engineer" who acts as the link between academic disciplines and professional techniques possess to effectively respond to the requirements of the changing research world? Is a data scientist for the humanities possible ${ }^{21}$ ? Are specific digital humanities positions desirable in large research organisations like the CNRS?

Although the position of a digital humanities engineer does not exist yet in higher education and research job profiles, more and more laboratories or human science centres wish to recruit "digital humanities" engineers to work on digital project management. Research organisations have yet to fully identify or define a job type for these professions which are often seen as "rare birds". A new profile is required for an enhanced engineer working at the crossroads between humanistic and technical cultures. Digital humanities engineers are recruited to advise and support HSS researchers in the use of digital technologies and take part in the life and structuring of HSS research in the digital environment within institutions and establishments. They help drive scientific activities by organising training courses and scientific events, helping to set up projects and carrying out scientific and technological monitoring. They develop new tools and bring researchers involved in the digital humanities together. Finally, they provide the interface between research teams and the national and international mechanisms that have been created over the last ten years such as the Digital Scientific Library (BSN) ${ }^{22}$, the CLEO ${ }^{23}$ and Huma-Num ${ }^{24}$ initially and more recently DARIAH ${ }^{25}$ and the Progedo Very Large Research Infrastructure $^{26}$. A great deal of knowledge and skills are required to implement these work missions. These include good knowledge of the field of digital humanities, the uses and practices of digital technology, knowledge modelling, the central issues of HSS research, web technologies, norms and standards and finally the rules and legal problems of copyright.

\footnotetext{
${ }^{20}$ More particularly see the paragraph on "L’ingénieur(e) HSS face au numérique : une rencontre interdisciplinaire" (The HSS engineer faced with the digital world: an interdisciplinary encounter) in [Massot, M.-L., 2014].

21 On this matter, see Serge Abiteboul's conference at the 2017 Digit_Hum Workshop: https://digithum.humanum.fr/atelier/2017/2_abiteboul.php consulted on 16/04/2021.

${ }^{22}$ The BSN was created in 2009 at the initiative of the French Ministry of Higher Education and Research and brought together many professionals from universities and research organisations. Its aim was to ensure that all academics, researchers or students have the relevant scientific information and the most efficient tools possible available to them. It was also a source of funding for the digitisation of libraries through calls for projects. It evolves, in 2018, into Open Science and becomes the Committee for Open Science (CoSO): http://www.bibliothequescientifiquenumerique.fr/ consulted on 20/09/2021.

${ }^{23}$ The Cléo is the structure that runs the OpenEdition portal, a set of electronic resource platforms in the humanities and social sciences: OpenEdition Books (book collections), Revues.org (journals), Hypotheses (research notebooks), Calenda (event announcements): https://journals.openedition.org/trivium/582 consulted on 20/09/2021.

${ }^{24}$ Huma-Num is a Very Large Research Infrastructure ("Très Grande Infrastructure de Recherche", TGIR) which works on facilitating the digital transition in humanities and social sciences research: http://www.huma-num.fr/consulted on 16/04/2021. ${ }^{25}$ DARIAH is a pan-European infrastructure for arts and humanities specialists who work with computational methods. It supports digital research and teaching of digital research methods: https://www.dariah.eu/consulted on 16/04/2021.

${ }^{26}$ PROGEDO is also a Very Large Research Infrastructure. Its aim is to develop the culture of data and to drive a policy on survey data for research in the social sciences: http://www.progedo.fr/ consulted on 16/04/2021.
} 
Between the tradition and the future of the humanities, this new kind of engineer must also be specialized in a number of advanced information analysis processes (data mining, text mining, statistics, 3D modeling, etc.), some of which were unknown to him or her even ten years ago, and which he or she must gradually appropriate through his or her discipline. The profile does not exist yet so typical recruitment profiles can be found in branches of activity $\mathrm{F}$ (Culture, Communication, Production and Dissemination of Knowledge), D (Humanities and Social Sciences) or E (Computer Science, Statistics and Scientific Computing) depending on the specificity of the corpora which need to be processed and the host laboratories or institutions. Defining a typical or ideal profile for a humanities expert is a highly elusive task as it falls between knowledge and know-how and between disciplinary and technical skills.

\section{TRAINING COURSES AND STRUCTURING FOR THE DIGITAL HUMANITIES}

How should people be trained for this hybrid job profile - which lies somewhere between the humanities and sciences, between knowledge and techniques - in a constant dialogue between the research world and other professionals? Is there a need for actual digital humanities recruitment or do the digital humanities provide support, an approach or a technique for researchers, data analysts and STI (scientific and technical information) professionals who specialise in certain disciplines?

The specificity and constantly transforming hybrid profile of the "digital humanist" mean it is not an easy position to train for. Is it even possible to train this type of professional? It seems preferable to initiate and encourage singular career paths, motivations and varied interests during initial and then ongoing training to mix skills and implement innovative projects. This means being more interested in unusual, rich, and complementary career paths than wellidentified standard profiles when recruiting collaborators for a digital project. Thus, at the Master's level, engineering students with a strong scientific base can acquire complementary knowledge in a humanities field and initiate innovative projects. Similarly, literary students who are interested in science and digital technology can acquire complementary computer science skills. These kinds of profiles of people who transmit knowledge and techniques between disciplines are even more necessary today in a world in which scientific innovations are often found at the interface between existing disciplines. For this reason, students need to be trained to acquire a dual humanistic and technical profile and then be offered work opportunities both in the academic sphere and in companies while encouraging evaluation of their work and their professional progression. A return to a general baccalauréat combining humanities and sciences would probably be very beneficial in helping to avoid disciplines being compartmentalised and in not frustrating curious students by forcing them to choose their career path too early. Serge Abiteboul's (Inria - ENS) lecture on the Profession of Data Scientist (Atelier Digit_Hum 2017) clearly testifies to this sometimes arbitrary compartmentalisation ${ }^{27}$. In this way, for no particular reason computer science has been "classed" with the hard sciences. In recent years, master's degrees devoted to the digital humanities ${ }^{28}$ or which include a component thereof have begun to be offered in universities or the French grandes écoles both throughout France and in other countries (Figure 5). For example, there is the master's degree in digital humanities at the ENSSIB (National School of Information and Library Science) called "Pratiques et méthodes en Humanités numériques" (Practices and methods in digital humanities) co-accredited by the universities of Lyon 2 and Lyon 3 and the École Normale

\footnotetext{
${ }^{27}$ https://hdl.handle.net/10670/1.ijw1xv consulted on 16/04/2021.

${ }_{28}$ For a list of the available master's degrees, see the interactive map "Les masters en humanités numériques en France" (Digital Humanities master's degrees in France) which was first published on the "Ressources" page of the Digit_Hum webside en 2020 and is continually updated: https://digithum.huma-num.fr/ressources/masters/ consulted on 16/04/2021.
} 
Supérieure de Lyon which began in 2016 or the "Digital Humanities" master's degree ${ }^{29}$ at Paris Sciences et Lettres University which started in September 2017. This new master's degree is run collaboratively by the École Nationale des Chartes, the École Normale Supérieure, the École Pratique des Hautes Etudes and the École des Hautes Etudes en Sciences Sociales. We could also mention many other master's degrees in Paris, Tours, Rouen, or Montpellier which all have their own specific features and are supported by research laboratories. Nevertheless, while these courses are associated with research teams, they are not linked to actual digital humanities laboratories. In fact, there does not seem to be a digital humanities research laboratory in France, whereas these exist, for example, in Switzerland (the Digital Humanities Laboratory set up by Frédéric Kaplan in 2012 at the École Polytechnique Fédérale de Lausanne) or in the United States where there have been such laboratories for the past ten years. France seems to have chosen instead to develop large research infrastructures in support of disciplinary laboratories and work with targeted funding. Some HSS research laboratories have also developed centres or areas dedicated to this theme. These are often cross-disciplinary support teams existing within a research group.

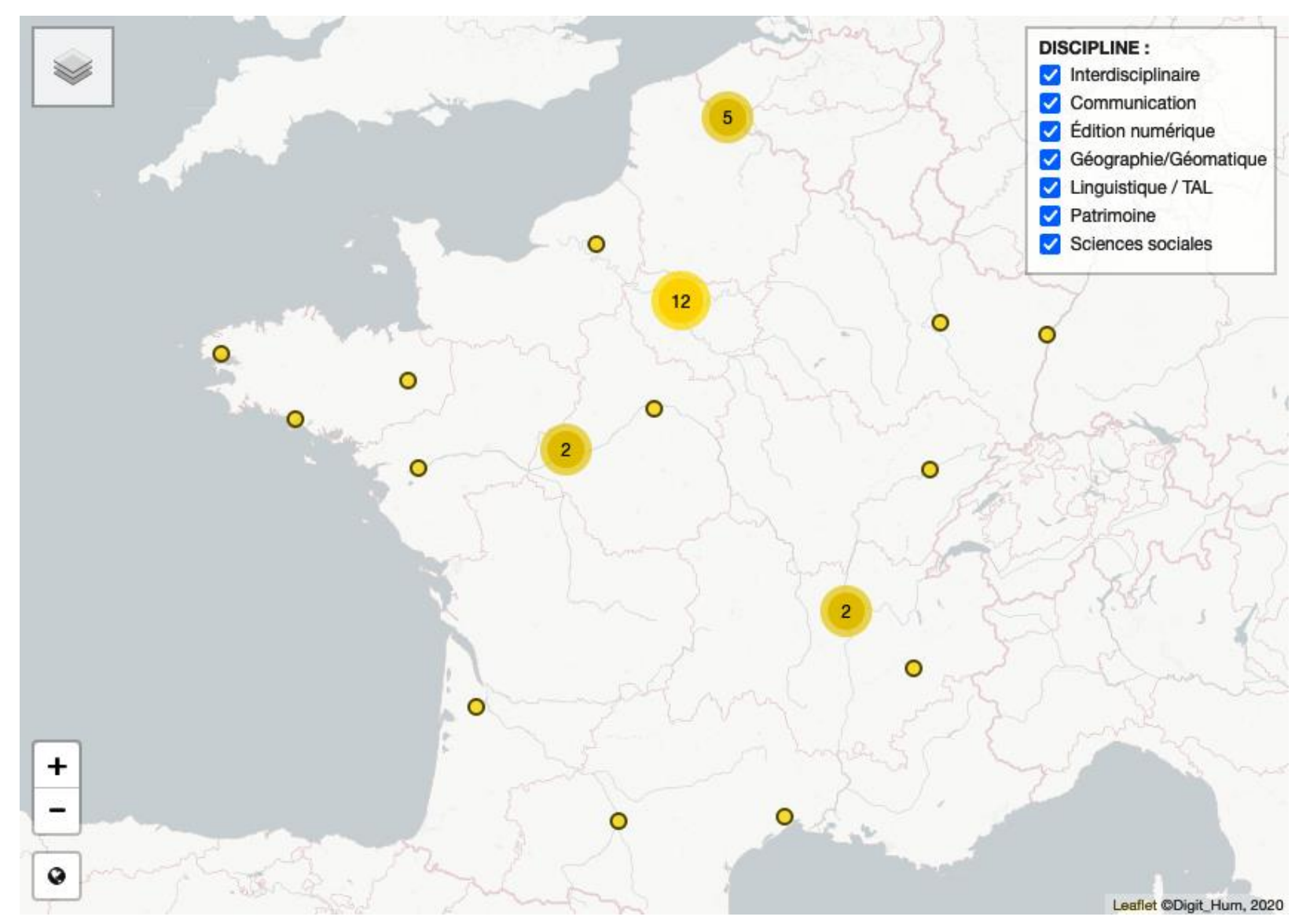

Figure 5. Digital Humanities master's degrees in France shown on the interactive map published on the Digit_Hum website (2020).

The aim of these courses is to provide students with a dual skill set combining in-depth abilities in a given discipline and in digital methods which will enable them to carry out their work independently as future researchers or engineers. Thus, students with a degree are trained in using and analysing data from the humanities while also deepening their knowledge of their

${ }^{29}$ https://www.univ-psl.fr/formation/humanites-numeriques consulted on 16/04/2021. 
own discipline (history and philosophy, literature, archaeology, etc.). The challenge for these interdisciplinary courses is to provide students with the dual skills they need to carry out independent research in the field of digital and computational humanities and thus lead to job opportunities in the teaching, research and business spheres. Some engineering schools like the École Fédérale Polytechnique de Lausanne (Master of Science in Digital Humanities) ${ }^{30}$, also offer Science and Digital Humanities courses. This kind of master's degree is aimed at engineers who already have a strong scientific background and are interested in digital innovations and culture in all its forms (music, history, etc.). In France, engineering schools do not seem to offer a dedicated digital humanities course and the courses we have identified are focused more on a disciplinary basis in the HSS with additional digital training.

These cross-disciplinary courses enable the barriers between disciplines to be broken down while increasing literary students' awareness of technical approaches and scientists' awareness of cultural questions. Also, a digital humanities course ${ }^{31}$ initiated by the director of the UlmJourdan library and set up in 2018 at the École Normale Supérieure testifies to the very important role libraries play in structuring the digital humanities. Libraries need to combine tradition and modernity and represent a place to be reinvented and hybridized to facilitate the transmission of knowledge and training of these new research actors.

These courses are all designed to train enlightened researchers (to be at least well-informed if not autonomous) and digital humanities engineers at the service of researchers to guide them in this new world. The humanities "enlightened" by digital technology and enhanced by the new possibilities offered by web technologies represent an academic field which is undergoing restructuring. The search for new forms of knowledge transmission is now part of the research process. The role of researcher-engineers is to experiment with new hypotheses and invent new forms within the framework of collaborative projects. They also need a taste for graphic design within the framework of the digital humanities which are still being constructed. Artistic creation, and especially digital design ${ }^{32}$ (art applied to the digital sphere), undoubtedly has a key role to play in this scientific renewal. Thus, [Clavert, F., 2015] presents design as a method for the Digital Humanities: "Therefore, we should massively integrate designers from the design culture into projects if we wish to ensure the digital humanities themselves are humanised and if we want to avoid abandoning them to the technical logic of just engineering. We need to work on achieving the highest quality of user experience in projects thanks to information design and data design (which are already present in the Digital Humanities to a certain extent) and even more so by systematically calling upon the global culture of design projects and the most recent methodologies that have emerged from this. These include usercentred design (UCD), interaction design (IxDA), user experience design (UX design), participative design (co-design), design thinking, design of services, policy design, design for social innovation, etc."

The traditional humanities therefore seem to be gradually integrating the possibilities of the digital sphere in their own way and at their own rhythm. The questions of the culture of permanent innovation and new forms of collaboration brought up by the digital humanities need to be approached in a context of teamwork where all involved contribute their scientific, technical or artistic expertise to the research project. The humanist engineer has a key role to

\footnotetext{
${ }^{30}$ https://cdh.epfl.ch/dh-master consulted on 16/04/2021.

${ }^{31} \mathrm{https}$ ://www.ens.psl.eu/une-formation-d-exception/formations/formations-aux-humanites-numeriques/cours-d-introductionaux consulted on 16/04/2021.

32 "In its interactive capacity, digital design is the profession that defines the form and response of digital products, services and interactive systems. Digital design is actually the field of creating websites, software, interactive objects and multimedia services. To achieve this, various activities need to be taken into consideration including the look, function, presentation and structuring of a product or service's content", definition given at the following address http://parisregards.fr/une-definition-dudesign-numerique/, consulted on 11/01/2021. Also see [Vial, S., 2012].
} 
play in this necessary dialogue between professionals but the collective paves the way for new lines of research and develops new humanities projects enhanced by the new opportunities digital technology offers. These hybrid cross-disciplinary profiles are necessary although very difficult to train ${ }^{33}$ and discover. Such engineers come from a disciplinary field and adapt digital technology to their practices and object of study. Rather than digital humanists, digital geographers, digital historians, digital philosophers, etc. need to initiated and then trained throughout their professional career. Digital humanists are required who perceive the important issues in disciplines and techniques without opposing them. They need to be open to other fields of study and wish to work at the interface between disciplines.

\section{CONCLUSION}

It is not a simple task to define the actors involved in the digital humanities because digital projects involve highly diverse professions which are undergoing profound change and redefinition. These include teaching and research professions, research support professions (HSS engineers, STI professionals), computer scientists, designers, lawyers and so forth. Research in the humanities and social sciences is tending to increasingly involve cooperation between actors and collaborative practices that dynamite the usual frameworks. Researchers or academics are responsible for initiating and carrying out innovative research as the true initiators of the dialogue between discipline and technique but engineers represent that dialogue in action. They act as true translators, transmitting techniques and methods, but also design and experiment with new tools while guiding researchers in their discoveries. They are at the interface between the humanities, computer science and design and are engaged in a constant dialogue between disciplines and techniques. They bridge the gap between researchers' ideas and technical innovation and between research and its application or tangible incarnation. Of course, training can help develop these cross-disciplinary profiles, especially to raise awareness and introduce new practices. It also seems essential to encourage and facilitate original lines of research.

Under these conditions, is the structuring of professions as it is presented today in French public research still adapted to the hybrid profiles in digital humanities that master's programs have been training for several years? Probably not. How can the current classification be changed to include these new skills? Should we consider creating a new family of activities or a new job type to take into account this now well-established reality? This would make it possible to promote these emerging profiles and improve recruitment conditions. But where to locate them in the current ecosystem? Isn't the business logic underlying the current classification inconsistent with the diversity of knowledge and skills that we would like to better integrate? In short, do we not run the risk of artificially compartmentalizing a category which does not actually exist, and whose plurality precisely creates all its richness? Clearly, one of the challenges of tomorrow's humanities and social sciences research lies in how to assimilate this new field of digital humanities, to support and recognize the value of people with mixed profiles who mediate between disciplines. Nevertheless, creating positions for digital humanities engineers does not mean, in our opinion, that HSS engineering profiles will disappear, but rather that new positions are needed for these disciplines to integrate new tools and new practices by opening the door to more transversal profiles. The digital sphere forces us to reinvent all aspects of Man, to rethink research and puts dialogue at the heart of its practice.

\footnotetext{
${ }^{33}$ It is interesting to note that more and more "traditional" master's degrees offer a mandatory introduction to the digital humanities in their basic training. Including some innovations of the digital humanities in masters traditionnaly reposing on books permited to be initiate on this new culture, this new way of making available and analyzing data.
} 


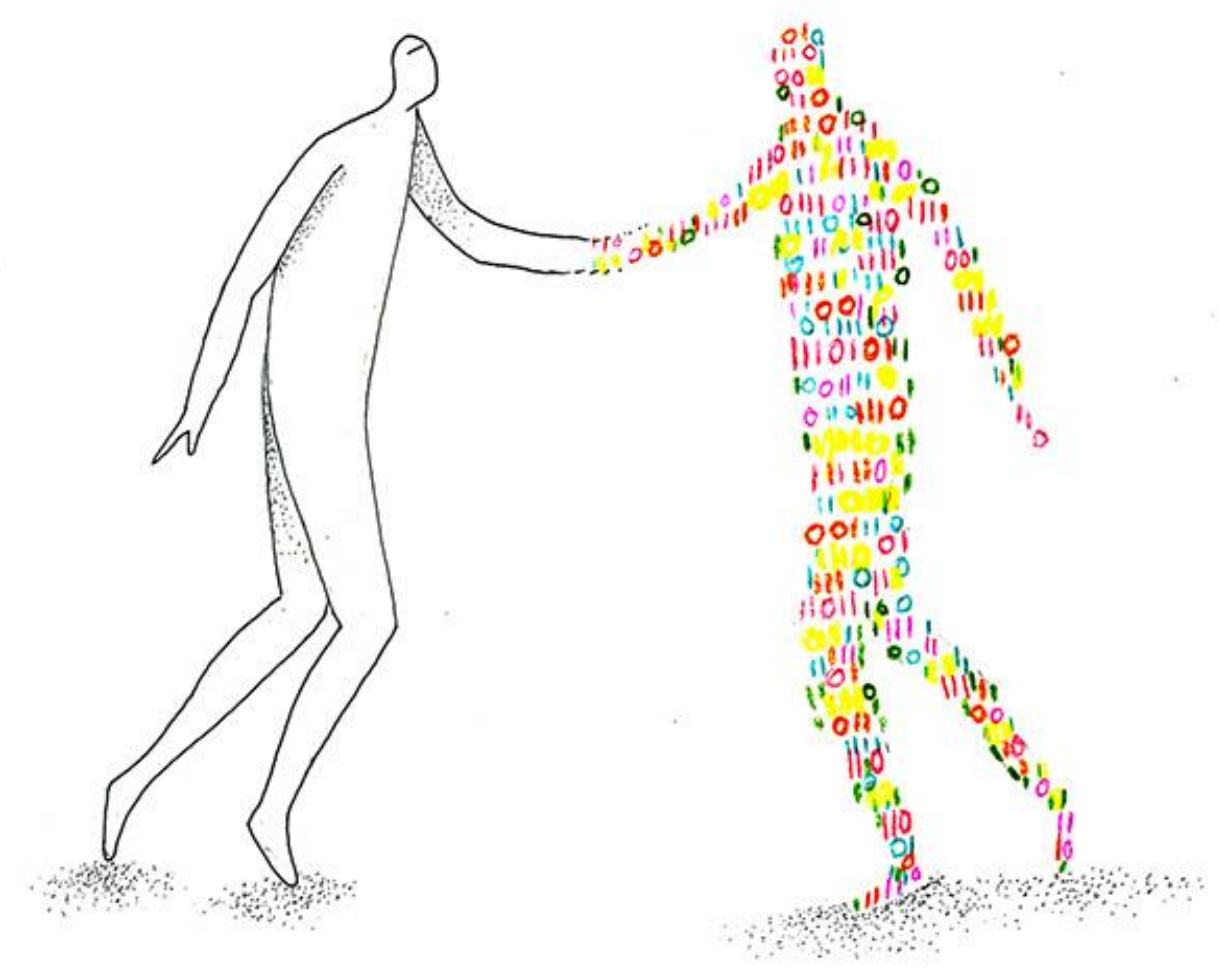

Figure 6. Drawing the digital humanities. Illustration by Saint-Oma, 2019.

\section{REFERENCES}

Bénel, A., Quelle interdisciplinarité pour les "humanités numériques" ? Les Cahiers Du Numérique. 2013 ; 10, vol. 4, p. 103132. DOI : $10.3166 / 1 \mathrm{cn} \cdot 10.4 .103-132$

Burdick, A., Drucker, J., Lunenfeld, P., Presner, T., Schnapp, J. Digital_Humanities. The Mit Press Cambridge, Massachusetts, London, England. 2012, p. 122.

Cartron, D. and al., Entre savoirs et savoir-faire, compétences disciplinaires et compétences techniques, les métiers des ingénieurs et techniciens en sciences humaines et sociales, rapport coordonné par D. Cartron, M. Bigoteau, F. Bouyer, A. Kieffer, O. Le Brun, M.-L. Savoye, S. Sanz, B. Simpson et R. Walter, Direction des ressources humaines, Observatoire des métiers et de l'emploi scientifique, Décembre 2012 : https://drh.cnrs.fr/wp-content/uploads/2020/01/Etude-BAP-D-2012.pdf

Cavero, J., Massot, M.-L., Tricoche, A., Digit_Hum : Humanités numérique entre savoir et savoir-faire. Site web de l'Initiative Digit_Hum. 2018-2021.

Clavert, F. 2DH - Design \& Digital Humanities : le design comme méthode pour les Humanités Numériques ? Ateliers Thatcamp, Paris 2015. Article consultable à l'adresse : https://tcp.hypotheses.org/849

Dacos, M. and Mounier, P., Humanités numériques : état des lieux et positionnement de la recherche française dans le contexte international, rapport, Paris, Institut français. 2014, p. 16.

Massot, M.-L. Humanités \& Numérique, Transformation des savoirs et des métiers. VRS, n³99, décembre 2014, p. 23-25.

Massot, M.-L., Tricoche, A., Acteurs et activités en humanités numériques à l’École Normale Supérieure : Enquête. [Rapport de recherche] CAPHES - UMS 3610 CNRS/ENS ; Labex TransferS (programme Investissements d'avenir ANR-10-IDEX0001-02 PSL* et ANR-10-LABX-0099) - Pôle Humanités Numériques. 2018. https://hal.archives-ouvertes.fr/hal-02103199v2

Massot, M.-L., Sforzini, A., Ventresque, V., Transcribing Foucault's handwriting with Transkribus. Journal of Data Mining and Digital Humanities, Episciences.org, 2019, Atelier Digit_Hum. https://jdmdh.episciences.org/5218/

Schlagdenhauffen, R., Optical Recognition Assisted Transcription with Transkribus: The Experiment concerning Eugène Wilhelm's Personnal Diary (1885-1951)». Journal of Data Mining and Digital Humanities, Episciences.org, 2020, Atelier Digit_Hum. https://jdmdh.episciences.org/6736/ 
Schmitt, E., La structuration disciplinaire et thématique des humanités numériques, Systèmes d'organisation des connaissances et humanités numériques. 2017, p. 25.

Vial, S., Qu'appelle-t-on le design numérique ?, Interfaces numériques, Lavoisier, De l'interactivité aux interaction(s) médiatrice(s), 2012;1/1, p.91-106, consultable sur Hal à l'adresse : $\underline{\text { https://hal.archives-ouvertes.fr/hal-01154867 }}$

\section{ACKNOWLEDGEMENTS}

Support by Translitteræ (École universitaire de recherche, program "Investissements d'avenir" ANR-10-IDEX-0001-02 PSL* and ANR-17-EURE-0025) 